Research article

\title{
XRCC1 and XPD genetic polymorphisms, smoking and breast cancer risk in a Finnish case-control study
}

\author{
Katja Metsola ${ }^{1}$, Vesa Kataja ${ }^{2}$, Pia Sillanpäää, Päivi Siivola ${ }^{1}$, Liisa Heikinheimo ${ }^{1}$, Matti Eskelinen ${ }^{3}$, \\ Veli-Matti Kosma ${ }^{4,5}$, Matti Uusitupa ${ }^{6}$ and Ari Hirvonen ${ }^{1}$
}

\author{
1Department of Industrial Hygiene and Toxicology, Finnish Institute of Occupational Health, Helsinki, Finland \\ 2Department of Oncology, Kuopio University Hospital, Kuopio, Finland \\ ${ }^{3}$ Department of Surgery, Kuopio University Hospital, Kuopio, Finland \\ ${ }^{4}$ Department of Clinical Pathology, Kuopio University Hospital, Kuopio, Finland \\ ${ }^{5}$ Department of Pathology and Forensic Medicine, University of Kuopio, Kuopio, Finland \\ ${ }^{6}$ Department of Clinical Nutrition, University of Kuopio, Kuopio, Finland
}

Corresponding author: Katja Metsola, katja.metsola@ttl.fi

Received: 8 Jul 2005 Revisions requested: 11 Aug 2005 Revisions received: 6 Sep 2005 Accepted: 19 Sep 2005 Published: 11 Oct 2005

Breast Cancer Research 2005, 7:R987-R997 (DOI 10.1186/bcr1333)

This article is online at: http://breast-cancer-research.com/content/7/6/R987

(c) 2005 Metsola et al.; licensee BioMed Central Ltd.

This is an Open Access article distributed under the terms of the Creative Commons Attribution License (http://creativecommons.org/licenses/by/ 2.0), which permits unrestricted use, distribution, and reproduction in any medium, provided the original work is properly cited.

\begin{abstract}
Introduction It has been suggested that individuals with reduced DNA repair capacities might have increased susceptibility to environmentally induced cancer. In this study, we evaluated if polymorphisms in DNA repair genes XRCC1 (Arg280His, Arg399GIn) and XPD (Lys751G/n) modify individual breast cancer risk, with emphasis on tobacco smoking.

Methods The study population consisted of 483 incident breast cancer cases and 482 population controls of Finnish Caucasian origin. The genotypes were determined by PCR-RFLP-based methods. Odds ratio (OR) and confidence intervals (Cls) were calculated by unconditional logistic regression analyses.

Results No statistically significant overall effect in the breast cancer risk was seen for any of the studied polymorphisms. However, a significant increase in breast cancer risk was seen among ever smoking women if they carried at least one XRCC1-

$399 \mathrm{GIn}$ allele (OR 2.33, 95\% Cl 1.30-4.19, $\left.p_{\text {int }} 0.025\right)$ or XPD$751 \mathrm{G} / n / \mathrm{G} / \mathrm{n}$ genotype (OR 2.52, 95\% Cl 1.27-5.03, $p_{\text {int }}$ 0.011 ) compared to smoking women not carrying these genotypes. The risks were found to be confined to women smoking at least five pack-years; the respective ORs were 4.14 (95\% Cl 1.66-10.3) and 4.41 (95\% Cl 1.62-12.0). Moreover, a significant trend of increasing risk with increasing number of the putative at-risk genotypes ( $p$ for trend 0.042) was seen. Women with at least two at-risk genotypes had an OR of 1.54 (95\% Cl 1.00-2.41) compared to women with no at-risk genotypes. Even higher estimates were seen for ever actively smoking women with at least two at-risk genotypes.

Conclusion Our results do not indicate a major role for XRCC1 and $X P D$ polymorphisms in breast cancer susceptibility, but suggest that they may modify the risk especially among smoking women.

\section{Introduction}

Breast cancer is the most common female cancer among western societies and its incidence increases constantly. Hormonal factors like early age at menarche, later age at menopause, later age at first full term pregnancy, and hormone replacement therapy are known to be the main risk factors for sporadic breast cancer [1,2]. Also, alcohol appears to contribute to the increased risk for this malignancy, whereas the

results concerning smoking are inconsistent [3-6]. The inconsistencies might be due to several factors. For instance, cigarette smoke increases the production of reactive oxygen species (ROS) and contains chemical carcinogens capable of forming DNA adducts [7], both implicated in carcinogenesis. On the other hand, tobacco smoke has been suggested to have an anti-estrogenic and, therefore, anti-carcinogenic effect [8]. It has also been suggested that the genetic background might modify the association between tobacco smoke and breast cancer [4].
\end{abstract}


Unrepaired or misrepaired DNA damage can lead to gene mutations, chromosomal alterations, and genomic instability, known to have a role in cancer initiation. Accordingly, individuals with reduced DNA repair capacities might have an altered cancer risk [9-11]. During recent years, several polymorphisms in the genes encoding the DNA repair enzymes have been found and studied in relation to cancer proneness $[12,13]$.

$\mathrm{XRCC1}$ (X-ray repair cross-complementing group 1 ) is known to participate in base excision repair (BER) of small lesions such as oxidized or reduced bases, fragmented or nonbulky adducts, and lesions caused by methylating agents [14]. The $\mathrm{XRCC} 1$ is a multidomain protein that has no known catalytic activity itself but it recruits DNA polymerase $\beta$, DNA ligase III and poly(ADP-ribose) polymerase (PARP) that are needed at the site of DNA damage [15].

Three gene polymorphisms resulting in non-conservative amino acid substitutions (Arg194Trp, Arg280His and Arg399GIn) have been identified in the XRCC1 gene [12]. Two of these (Arg280His and Arg399GIn) were recently predicted to be likely to affect the function of the protein based on the conservation of the amino acids among protein family members [16]. The XRCC1 Arg280His polymorphism lies in between the DNA polymerase $\beta$ and PARP binding areas [17]. The 280 His variant allele has been suggested to confer increased mutagen sensitivity [18] and breast cancer risk [19], although contrasting results exist [20-22].

The XRCC1 Arg399G/n polymorphism is located in the area coding for a PARP binding site. PARP is a zinc-finger containing enzyme that detects DNA strand breaks [23]. Carriers of the XRCC1-399 G/n variant allele have been shown to have higher levels of DNA adducts [20] and to be at greater risk for ionizing radiation sensitivity [24] and tobacco-related DNA damage [25-27]. A positive association between the 399G/n variant allele and breast cancer risk has been seen in some studies $[21,22,28,29]$ while no overall association has been seen in others $[19,29-36]$.

The nucleotide excision repair (NER) pathway repairs a wide variety of DNA damage, including cross-links, oxidative damage and bulky adducts (such as polycyclic aromatic hydrocarbon (PAH)-DNA adducts). The XPD (XP complementation group $D)$ gene encodes a helicase involved in transcription and in the NER pathway by unwinding of double helix at the site of deleterious DNA lesions [37]. Several single nucleotide polymorphisms (SNPs) have been described in the XPD gene. Two of these SNPs lead to amino acid change, Asp312Asn in exon 10 and Lys751GIn in exon 23, and are in strong linkage disequilibrium with each other $[12,38]$. The $X P D-751 \mathrm{Gln}$ variant allele has been associated with increased DNA adduct levels $[39,40]$ and suboptimal DNA repair $[11,38]$, but contrasting results also exist [41]. It has recently been associated with increased risk of smoking-related cancers, such as lung cancer [42] and squamous cell carcinoma of head and neck [43], and recently a significant effect was also seen for breast cancer [44]. Contrasting results also exist [11,40,45-47].

In this study, we evaluated the role of XRCC1 Arg280His, XRCC1 Arg399G/n, and XPD Lys751G/n polymorphisms in breast cancer susceptibility in our Finnish Caucasian study population. We especially aimed at examining the genotype effects in relation to smoking, which is known to cause DNA damage repaired by DNA repair enzymes of the BER and NER pathways. The role of alcohol was also evaluated in this context.

\section{Materials and methods Study population}

Breast cancer cases had been referred by a physician to the Kuopio University Hospital (Finland) during the recruiting period from 1990 to 1995 because of a suspect breast sign or symptom. Women were asked to participate in the study and were interviewed by a trained study nurse before any diagnostic procedures. The study was approved by the Joint Committee of the University of Kuopio and Kuopio University Hospital. Participation was based on written consent.

A total of 516 out of 1,919 women were eventually diagnosed with histologically confirmed breast cancer. The details of the study population and recruitment have been described earlier [48]. The contact rate for the cases, calculated as described in [49], was $86 \%$, the cooperation rate was $98 \%$, and the overall response rate $84 \%$.

Healthy population controls living in the same area as the cases were a randomly selected group of subjects drawn from the Finnish National Population register. They were initially contacted by a letter explaining the study protocol, and subsequently called up and invited to the hospital to be interviewed. In all, 514 controls were interviewed in parallel with the cases, all of whom agreed to participate in a genetic study. The cooperation rate for the controls was $72 \%$.

Blood samples were collected at the time of the interview. Lymphocyte DNA was available for 483 breast cancer patients and 488 controls. Six subjects among controls were excluded, four because of earlier breast cancer diagnosis and two because of non-Finnish origin. The final case group included 483 cases (mean age 58.9 years, range 44.3 to 91.6 ) and 482 controls (mean age 53.5 years, range 37.5 to 77.2 ), all of Finnish Caucasian origin.

Detailed data on smoking habits included the amount of cigarettes with or without filter/day, years of smoking, time since quitting smoking, and time (in years) of passive smoking at home and/or at work. 


\section{Genotyping analyses}

Lymphocyte DNA (100 ng) extracted by standard methods was used as a template in PCR-based restriction fragment length polymorphism (RFLP) assays. For the XRCC1 Arg280His genotype determination, a 282 base pair (bp) fragment was amplified using the primers described earlier [18]. After digestion of the PCR product with $3 \mathrm{U}$ of Rsal, the 280 Arg wild-type allele was revealed by two $141 \mathrm{bp}$ fragments, while an intact $282 \mathrm{bp}$ fragment indicated the presence of the 280 His variant allele.

In the XRCC1 Arg399GIn genotype analysis, a 615 bp fragment amplified using the primers described in [20] was digested with $3 \mathrm{U}$ of $M s p l$ restriction enzyme; the XRCC1-399 Arg wild-type allele was revealed by the presence of $221 \mathrm{bp}$ and $374 \mathrm{bp}$ fragments while the $399 \mathrm{G} / \mathrm{n}$ variant allele remained intact (615 bp).

The XPD Lys751G/n genotypes were determined by amplifying a $324 \mathrm{bp}$ fragment with the primers described in [50]. The resulting fragment was digested with $3 \mathrm{U}$ of $P$ stl; the amplicon from the 751 Lys wild-type allele was cut into 220 bp and 104 bp fragments while the amplicon from the $751 \mathrm{G} / n$ variant allele was cut into $157 \mathrm{bp}, 104 \mathrm{bp}$ and $63 \mathrm{bp}$ fragments.

The genotype analyses were performed unaware of the casecontrol status. Two positive controls with known genotype and two negative controls were used within each PCR amplification batch, and two independent researchers interpreted the gel images to ensure the validity of genotyping for each polymorphism. The PCR for samples with divergent results was repeated and an additional $10 \%$ of all samples were reanalysed for each polymorphism for quality control. No discrepancies were found in the replicate tests. The XRCC1 Arg280His genotype could not be determined for three cases and three controls, the Arg399G/n genotype for four cases and four controls, and the XPD Lys751G/n genotype for two cases and two controls.

\section{Statistical analyses}

Association between genotypes and risk of breast cancer were evaluated by unconditional logistic regression to calculate multivariate adjusted odds ratios (ORs) and 95\% confidence intervals (Cls) using SPSS version 11.5 (SPSS Inc., Chicago, Illinois, USA). Calendar age, age at menarche, age at first full term pregnancy, number of children, history of benign breast diseases, first degree (mother, sister, daughter) family history of breast cancer, waist-to-hip ratio and use of alcohol and smoking were used as adjusting variables in all analyses. Subjects with missing values in any of the adjusting variables were excluded from the analysis. When the adjusted ORs differed significantly from the unadjusted ORs, both are shown.

Women who had smoked daily for longer than three months were considered as smokers. Never smokers were catego-
Table 1

Selected characteristics of the study subjects

\begin{tabular}{lcc}
\hline Characteristic & Case/control $^{\mathrm{a}}$ & $\mathrm{OR}^{\mathrm{b}}(95 \% \mathrm{Cl})$ \\
\hline Age at menarche & & \\
$\leq 12$ & $98 / 101$ & 1.0 \\
$13-14$ & $219 / 251$ & $0.82(0.59-1.16)$ \\
$\geq 15$ & $150 / 127$ & $0.99(0.68-1.46)$
\end{tabular}

Age at first full-term pregnancy

Nulliparous
$\leq 25$
$26-30$
$\geq 31$

$\begin{array}{cc}102 / 57 & 1.0 \\ 237 / 263 & 0.55(0.38-0.81) \\ 94 / 122 & 0.44(0.29-0.69) \\ 47 / 40 & 0.64(0.36-1.12)\end{array}$

Number of full-term pregnancies

Nulliparous
1
2
$3+$
Waist-to-hip ratio
$\leq 0.91$
$>0.91$
First-degree family history of
breast cancer
No
Yes

$\begin{array}{cc}102 / 57 & 1.0 \\ 68 / 64 & 0.59(0.36-0.98) \\ 141 / 181 & 0.50(0.33-0.76) \\ 171 / 180 & 0.54(0.36-0.80)\end{array}$

$187 / 236 \quad 1.0$

$291 / 243 \quad 1.38(1.06-1.81)$

History of benign breast disease

$\begin{array}{lcc}\text { No } & 296 / 313 & 1.0 \\ \text { Yes } & 180 / 167 & 1.33(1.01-1.75)\end{array}$

Current alcohol intake

$\begin{array}{lcc}\text { Never } & 271 / 206 & 1.0 \\ \text { Once a month or less } & 134 / 187 & 0.74(0.54-1.01) \\ \text { Daily-weekly } & 75 / 89 & 0.87(0.59-1.29)\end{array}$

Smoking habits

Never active or passive

Passive only

$210 / 182 \quad 1.0$

Ever active

$153 / 169 \quad 0.78(0.58-1.06)$

$<5$ pack-years

$112 / 130 \quad 0.91(0.65-1.28)$

$\geq 5$ pack-years

$45 / 63$

$0.75(0.48-1.16)$

67/67 $1.08(0.72-1.62)$

a Total number of cases and controls does not correspond because of missing values.

${ }^{b}$ Adjusted for age. $\mathrm{Cl}$, confidence interval; OR, odds ratio. 
rized as those who had never been exposed to either passive or active smoking, and as those exposed to passive smoking only. Ever smokers were further categorized according to the approximate median smoking years ( 15 years), daily consumption (10 cigarettes) and pack-years of smoking (5 pack-years) in the control population. Pack-years of cigarettes were calculated as the number of packs (20 cigarettes/pack) smoked per day multiplied by years of smoking.

Based on the prior knowledge of the functional significance or epidemiological evidence, the XRCC1-280 Arg/Arg and XRCC1-399 Arg/Arg genotypes were used as reference categories for all separate analyses. As the frequency of the $X R C C 1-280$ His variant allele was low, the ORs were calculated for the combined XRCC1-280 His allele containing genotypes in all analyses. Similarly, in the stratified analyses, the XRCC1-399 Gln allele containing genotypes were combined to increase statistical power. In contrast, a recessive model was used for the XPD Lys751G/n polymorphism based on the observed genotype distributions and some earlier publications [42,51]. Therefore, the heterozygous XPD-751 Lys/GIn genotype was combined with the wild-type Lys/Lys genotype to serve as a reference category. Possible gene environment interactions were assessed using stratified analyses and interaction terms. Variables of interest were smoking and use of alcohol. Tests for interactions were assessed by the likelihood ratio test to compare goodness of fit of the model with the interaction term, to the reduced model including the main effect variable (genotype) and the main adjusting variables. All reported $p$-values are two-sided. No attempt was made to adjust for multiple comparisons.

\section{Results}

Characteristics of the study population are shown in Table 1. Parity was associated with decreased risk of breast cancer while higher waist-to-hip ratio, first degree family history of breast cancer and history of benign breast disease were associated with increased risk. No significant associations were seen between breast cancer risk and smoking habits. Neither were any statistically significant differences seen in the mean number of cigarettes smoked per day (mean 11.2, SD 9.2, and mean 9.5, SD 6.7, for cases and controls, respectively, $p=$ 0.10 ), or in smoking years (16.1, SD 10.8, and 14.5, SD 10.8, for cases and controls, respectively, $p=0.25$ ).

The frequencies of the XRCC1-280 His, XRCC1-399 G/n, and $X P D-751 \mathrm{G} / n$ variant alleles in controls were $0.08,0.27$, and 0.43 , respectively. All the genotype distributions in the control population conformed to Hardy-Weinberg equilibrium ( $p=0.993, p=0.657$, and $p=0.876$ for XRCC1-280, $X R C C 1-399$, and $X P D-751$ locuses, respectively). No statistically significant differences were seen in the frequency of these genotypes between cases and controls (Table 2). Neither was any significant difference seen for the polymorphisms when stratified by menopausal status or age (data not shown).
Table 2

Association between XRCC1 and XPD polymorphisms and breast cancer risk

\begin{tabular}{|c|c|c|c|}
\hline Genotype & Cases (\%) & Controls (\%) & OR $(95 \% \mathrm{Cl})^{a}$ \\
\hline \multicolumn{4}{|l|}{$X R C C 1-280$} \\
\hline Arg/Arg & 399 (83.1) & $406(84.8)$ & 1.0 \\
\hline $\mathrm{Arg} / \mathrm{His}$ & 78 (16.3) & $70(14.6)$ & \\
\hline His/His & $3(0.6)$ & $3(0.6)$ & $1.15(0.80-1.66)^{\mathrm{b}}$ \\
\hline \multicolumn{4}{|l|}{ XRCC1-399 } \\
\hline Arg/Arg & $237(49.5)$ & $256(53.6)$ & 1.0 \\
\hline $\operatorname{Arg} / G / n$ & $196(40.9)$ & $185(38.7)$ & $1.24(0.93-1.65)$ \\
\hline$G / n / G / n$ & $46(9.6)$ & $37(7.7)$ & $1.39(0.84-2.29) \mathrm{c}$ \\
\hline $\operatorname{Arg} / G / n+G / n / G / n$ & $242(50.5)$ & $222(46.4)$ & $1.26(0.96-1.66)$ \\
\hline \multicolumn{4}{|l|}{$X P D-751$} \\
\hline Lys/Lys & $147(30.6)$ & 155 (32.3) & 1.0 \\
\hline Lys/Gln & $238(49.5)$ & $237(49.4)$ & $1.03(0.76-1.40)$ \\
\hline$G / n / G / n$ & $96(20.0)$ & 88 (18.3) & $1.10(0.74-1.63)$ \\
\hline Lys/Lys+Lys/GIn & $385(80.0)$ & $325(81.7)$ & 1.0 \\
\hline$G / n / G / n$ & $96(20.0)$ & 88 (18.3) & $1.08(0.77-1.53)$ \\
\hline
\end{tabular}

aOdds ratios (ORs) and confidence intervals (Cls) adjusted for age, age at menarche, age at first full term pregnancy, number of pregnancies, history of benign breast disease, first degree family history of breast cancer, weist-to-hip ratio, smoking and use of alcohol. bOR for $\mathrm{Arg} / \mathrm{His}$ and His/His genotypes combined. ${ }^{\mathrm{c}} \mathrm{p}$ for trend $=0.105$.

When subjects were studied by the stage of the disease at the time of diagnosis, a significant increase for advanced stage (III or IV) breast cancer was seen for women with the XRCC1$399 \mathrm{G} / \mathrm{n} / \mathrm{G} / \mathrm{n}$ genotype (OR 2.86, 95\% Cl 1.05-7.81) compared to those with the Arg/Arg genotype. No increase in risk was seen for lower stage (I or II) breast cancer (OR 1.33, 95\% Cl 0.79-2.26). A similar tendency of increased risk for advanced stage cancer was seen for subjects with the XRCC1-280 Arg/His or His/His genotype (OR 1.99, 95\% Cl 0.90-4.42) compared to subjects with the Arg/Arg genotype. Similarly, women with the XRCC1-399 G/n/GIn genotype presented with a significantly increased risk for grade II and grade III tumours (OR 1.80, 95\% Cl 1.06-3.07) when compared to those with the Arg/Arg genotype, while no increase was seen for grade I tumours (OR 1.10, 95\% $\mathrm{Cl} 0.75-1.62$ ). Moreover, women who carried the XRCC1-399 G/n/G/n genotype and were diagnosed with early stage (I or II) breast cancer had tumours of higher grade (II or III) marginally ( $p=0.065$, onesided) more often than those with the Arg/Arg genotype, $86.1 \%(31 / 36)$ versus $72.5 \%(137 / 189)$, respectively.

When the association between XRCC1-399 genotypes and breast cancer risk was studied according to smoking habits, increased breast cancer risk with dose-response was seen among women who had ever smoked actively and carried either one (OR 2.14, 95\% Cl 1.15-3.97) or two (OR 3.27, 
Table 3

\begin{tabular}{|c|c|c|c|c|c|c|c|c|c|}
\hline \multirow[t]{2}{*}{ Genotype } & \multicolumn{3}{|c|}{ Never active or passive smoking } & \multicolumn{3}{|c|}{ Only passive smoking } & \multicolumn{3}{|c|}{ Active smoking } \\
\hline & Cases (\%) & $\begin{array}{c}\text { Controls } \\
(\%)\end{array}$ & OR $(95 \% \mathrm{Cl})^{\mathrm{a}}$ & Cases (\%) & $\begin{array}{c}\text { Controls } \\
(\%)\end{array}$ & OR $(95 \% \mathrm{Cl})^{\mathrm{a}}$ & $\begin{array}{c}\text { Cases } \\
(\%)\end{array}$ & $\begin{array}{c}\text { Controls } \\
(\%)\end{array}$ & OR $(95 \% \mathrm{Cl})^{\mathrm{a}}$ \\
\hline \multicolumn{10}{|l|}{$X R C C 1-280$} \\
\hline $\operatorname{Arg} / \operatorname{Arg}$ & $177(84.7)$ & $154(84.6)$ & 1.0 & $120(79.5)$ & $140(83.8)$ & 1.0 & $94(83.9)$ & $111(86.0)$ & 1.0 \\
\hline Arg/His+His/His & $32(15.3)$ & $28(15.4)$ & $1.09(0.60-1.99)$ & $31(20.5)$ & $27(16.2)$ & $1.11(0.59-2.08)$ & $18(16.1)$ & $18(14.0)$ & $1.41(0.65-3.08)$ \\
\hline \multicolumn{10}{|l|}{ XRCC1-399 } \\
\hline Arg/Arg & $118(56.5)$ & $89(48.9)$ & 1.0 & $72(47.7)$ & $91(54.5)$ & 1.0 & $45(40.5)$ & $75(58.6)$ & 1.0 \\
\hline $\operatorname{Arg} / G / n$ & $76(36.4)$ & $76(41.8)$ & $0.83(0.53-1.31)$ & $67(44.4)$ & $66(39.5)$ & $1.40(0.84-2.32)$ & $49(44.2)$ & $43(33.6)$ & $2.14(1.15-3.97)$ \\
\hline$G / n / G / n$ & $15(7.2)$ & $17(9.3)$ & $0.73(0.33-1.64)$ & $12(7.9)$ & $10(6.0)$ & $1.61(0.61-4.23)$ & $17(15.3)$ & $10(7.8)$ & $3.27(1.25-8.58)^{b}$ \\
\hline $\operatorname{Arg} / G / n+G / n / G / n$ & $91(43.5)$ & $93(51.1)$ & $0.81(0.53-1.25)$ & 79 (52.3) & $76(45.5)$ & $1.42(0.87-2.32)$ & $66(59.5)$ & $53(41.4)$ & $2.33(1.30-4.19)^{\mathrm{c}}$ \\
\hline \multicolumn{10}{|l|}{$X P D-751$} \\
\hline Lys/Lys & $66(31.6)$ & $58(31.9)$ & 1.0 & $40(26.3)$ & 56 (33.3) & 1.0 & $40(35.7)$ & $40(31.0)$ & 1.0 \\
\hline Lys/G/n & 109 (52.2) & $91(50.0)$ & $1.03(0.63-1.66)$ & $83(54.6)$ & $77(45.8)$ & $1.35(0.78-2.34)$ & $40(35.7)$ & $77(45.8)$ & $0.68(0.35-1.33)$ \\
\hline$G / n / G / n$ & 34 (16.3) & $33(18.1)$ & $0.78(0.40-1.49)$ & $29(19.1)$ & $35(20.8)$ & $0.84(0.41-1.69)$ & $32(28.6)$ & $35(20.8)$ & $1.96(0.89-4.32)$ \\
\hline Lys/Lys+Lys/Gln & $175(83.7)$ & $149(81.9)$ & 1.0 & $123(80.9)$ & $133(79.2)$ & 1.0 & $80(71.4)$ & $109(84.5)$ & 1.0 \\
\hline$G / n / G / n$ & $34(16.3)$ & $33(18.1)$ & $0.77(0.43-1.39)$ & $29(19.1)$ & $35(20.8)$ & $0.70(0.38-1.29)$ & $32(28.6)$ & $20(15.5)$ & $2.52(1.27-5.03)^{d}$ \\
\hline
\end{tabular}

aOdds ratios (ORs) and confidence intervals (Cls) adjusted for age, age at menarche, age at first full term pregnancy, number of pregnancies, history of benign breast disease, first degree family history of breast cancer, weist-to-hip ratio and use of alcohol. ${ }^{b} p$ for trend $=0.003$. clnteraction between smoking habits and XRCC1-399 genotype $(p=0.025)$. IInteraction between smoking habits and XPD-751 genotype $(p=0.011)$.

95\% Cl 1.25-8.58, $p$ for trend=0.003) XRCC1-399 G/n variant alleles compared to those carrying the Arg/Arg genotype ( $p$ for interaction between smoking habits and XRCC1-399 genotype 0.025) (Table 3). A similar increase in risk was seen for ever smoking women with the XPD-751 G/n/G/n genotype compared to ever smoking women without this genotype (OR 2.52, 95\% Cl 1.27-5.03, $p$ for interaction 0.011).

When ever smoking women were further stratified by packyears smoked $(<5, \geq 5$ pack-years), the increase in risk was seen to be confined to those who had smoked over five packyears and carried at least one XRCC1-399 G/n allele (OR $4.14,95 \% \mathrm{Cl} 1.66-10.3)$, or the XPD-751 G/n/G/n genotype (OR 4.41, $95 \% \mathrm{Cl}$ 1.62-12.0) compared to similarly smoking women without these genotypes (Table 4). Similar effects were seen for the XRCC1 Arg399GIn genotypes when smokers were stratified by daily tobacco consumption $(<10, \geq 10$ cigarettes/day) or by smoking years $(<15, \geq 15$ years). The ORs were 5.32 (95\% Cl 1.97-14.4) for women smoking $\geq 10$ cigarettes/day and carrying at least one XRCC1-399 G/n allele, and 4.03 (95\% Cl 1.40-11.6) for women who had smoked $\geq 15$ years and carried at least one XRCC1-399 G/n allele, compared to women with similar smoking habits but with the XRCC1-399 Arg/Arg genotype. For the carriers of the $X P D-751 \mathrm{G} / \mathrm{n} / \mathrm{G} / \mathrm{n}$ genotype, a similar increase in the risk of breast cancer was seen for women smoking $\geq 10$ cigarettes/ day (OR 4.78, 95\% Cl 1.50-15.2) while no statistically significant increase was seen by smoking years (OR 2.25, 95\% Cl
0.85-5.96 for women smoking $\geq 15$ years), compared to women smoking the same amount, but not carrying the homozygous variant $X P D-751 \mathrm{G} / \mathrm{n} / \mathrm{G} / \mathrm{n}$ genotype.

When stratified by current use of alcohol, women who reported using alcohol weekly to daily and carried the $X P D$ $751 \mathrm{G} / \mathrm{n} / \mathrm{G} / \mathrm{n}$ genotype were at 3.18-fold (95\% Cl 1.34-7.57) increased risk of breast cancer compared to similarly drinking women carrying the other genotypes ( $p$ for interaction 0.026). No interaction was found between $X R C C 1-280$ or XRCC1399 genotypes and current use of alcohol (data not shown).

When the joint effect of the XRCC1-280, XRCC1-399, and $X P D-751$ genotypes was studied, a statistically significant increase in the risk of breast cancer was seen for subjects carrying two at-risk genotypes of these genes (OR 1.54, 95\% Cl 1.00-2.37) compared to subjects with the wild-type genotypes for all three polymorphic sites (Table 5). This increase was mainly due to the combined effect of XRCC1-399 and $X P D-751$ genotypes (OR 1.80, 95\% Cl 1.05-3.08, $p$ for gene-gene interaction 0.043). A trend of increasing risk with increasing number of at-risk genotypes was seen ( $p$ for trend 0.042). However, this estimate did not reach statistical significance (OR 4.76, 95\% Cl 0.48-47.8), possibly due to the low number of subjects with all the three at-risk genotypes (four cases and one control). When the combined effects were studied among ever active smokers, women who carried any two at-risk genotypes were at remarkably increased risk of 
Table 4

The association between XRCC1 and XPD genotypes and breast cancer risk according to pack-years smoked

\begin{tabular}{|c|c|c|c|c|c|c|}
\hline & \multicolumn{3}{|c|}{$<5$ pack-years } & \multicolumn{3}{|c|}{$>5$ pack-years } \\
\hline & Cases n (\%) & Controls n (\%) & OR $(95 \% \mathrm{Cl})^{\mathrm{a}}$ & Cases n (\%) & Controls n (\%) & OR $(95 \% \mathrm{Cl})^{\mathrm{a}}$ \\
\hline \multicolumn{7}{|l|}{ XRCC1-280 } \\
\hline Arg/Arg & $37(82.2)$ & $51(82.3)$ & 1.0 & $57(85.1)$ & $60(89.6)$ & 1.0 \\
\hline Arg/His+His/His & $8(17.8)$ & $11(17.7)$ & $0.91(0.28-2.95)$ & $10(14.9)$ & $7(10.4)$ & $1.99(0.57-7.02)$ \\
\hline \multicolumn{7}{|l|}{ XRCC1-399 } \\
\hline Arg/Arg & $20(44.4)$ & $35(57.4)$ & 1.0 & $25(37.9)$ & $40(59.7)$ & 1.0 \\
\hline $\operatorname{Arg} / G / n$ & $18(40.0)$ & $22(36.1)$ & $1.21(0.46-3.18)$ & $31(47.0)$ & $21(31.3)$ & $4.31(1.66-11.2)$ \\
\hline$G / n / G / n$ & $7(15.6)$ & $4(6.6)$ & $3.99(0.82-19.4)$ & $10(15.2)$ & $6(9.0)$ & $3.55(0.81-15.6)$ \\
\hline$A r g / G / n+G / n / G / n$ & $25(55.6)$ & $26(42.6)$ & $1.61(0.64-4.06)$ & $41(62.1)$ & $27(40.3)$ & $4.14(1.66-10.3)$ \\
\hline \multicolumn{7}{|l|}{$X P D-751$} \\
\hline Lys/Lys & $18(40.0)$ & $20(32.3)$ & 1.0 & $22(32.8)$ & $20(29.9)$ & 1.0 \\
\hline Lys/Gln & $18(40.0)$ & $31(50.0)$ & $1.01(0.37-2.77)$ & $22(32.8)$ & $38(56.7)$ & $0.40(0.14-1.12)$ \\
\hline$G / n / G / n$ & $9(20.0)$ & $11(17.7)$ & $1.59(0.44-5.74)$ & $23(34.3)$ & $9(13.4)$ & $2.77(0.90-8.59)$ \\
\hline Lys/Lys+Lys/GIn & $36(80.0)$ & $51(82.3)$ & 1.0 & $44(65.7)$ & $58(86.6)$ & 1.0 \\
\hline$G / n / G / n$ & $9(20.0)$ & $11(17.7)$ & $1.45(0.46-4.56)$ & $23(34.3)$ & $9(13.4)$ & $4.41(1.62-12.0)$ \\
\hline
\end{tabular}

aOdds ratios (ORs) and confidence intervals (Cls) adjusted for age, age at menarche, age at first full term pregnancy, number of pregnancies, history of benign breast disease, first degree family history of breast cancer, weist-to-hip ratio and use of alcohol.

breast cancer; the adjusted OR was 10.7 (95\% Cl 3.6231.6) compared to those without these genotypes (Table 5). This effect was mainly confined to combination of XRCC1399 and $X P D-751$ at-risk genotypes (OR 12.1, 95\% Cl 3.5241.5). When the combined effect was calculated for the number of at risk alleles (XRCC1-280 His, XRCC1-399 Gln and $X P D-751 \mathrm{G} / \mathrm{n}$ ), a similar increase in the risk was seen; subjects with three at-risk alleles had an OR of $1.72(95 \% \mathrm{Cl}$ 1.03-2.87; $p$ for trend 0.069) among all women, and OR 4.62 (95\% Cl 1.56-13.7; $p$ for trend 0.01) among ever actively smoking women compared to women with no at-risk alleles. Only four cases and one control carried simultaneously four atrisk alleles, and none more than four (of the six).

\section{Discussion}

In this study, we examined the role of XRCC1 Arg280His, XRCC1 Arg399GIn and XPD Lys751G/n polymorphisms in relation to breast cancer risk in a Finnish study population. As the products of these genes act in BER and NER pathways, and as some evidence exists on the association of these polymorphisms with smoking-related cancers [13,42,43,52], our special interest was to study the role of these DNA repair enzymes among smoking women. The hypothesis was also supported by a recent finding of an association between the $X P D-751 \mathrm{G} / \mathrm{n} / \mathrm{G} / \mathrm{n}$ genotype and breast cancer risk in smoking women [44].
The two polymorphisms Arg280His and Arg399GIn in the coding region of the $X R C C 1$ gene were recently predicted to be 'possibly damaging' to XRCC1 function based on the conservation of the sequences in mammalian orthologues [16]. In agreement with this, the frequency of the variant XRCC1-399 GIn allele was somewhat higher among the present cases compared to controls, leading to a tendency of increased breast cancer risk. A similar effect has been reported in studies among Korean [28], US radiologic technologists [21], Indian [22], and African-American [29] women. No increased risk was found for white American women [29], in agreement with three other studies performed among American women [30-33]. Moreover, no association was seen in studies among Chinese [35], French [19], Canadian [34], Turkish [36] and Danish [46] women.

In contrast to the XRCC1 Arg399GIn polymorphisms, the Arg280His polymorphism did not significantly modify breast cancer risk in the present study. Similarly, no association was seen for Indian women [22] or for US radiologic technologists [21]. On the other hand, our findings are in contrast to a French study showing a 1.8 -fold $(95 \% \mathrm{Cl} 1.04-3.08)$ increase in breast cancer risk for the XRCC1-280 Arg/His genotype [19]. One reason for this divergence could be the lack of power; the frequency of the 280 His allele is low (0.08) among Caucasians, including Finns. Consequently, even though having almost twice the size of the French study, the power of our study to detect an OR of 1.5 at a 0.05 significance level was 
Table 5

\begin{tabular}{|c|c|c|c|c|c|c|c|c|c|}
\hline \multirow[b]{2}{*}{$\begin{array}{l}\text { No of at risk } \\
\text { genotypes }\end{array}$} & \multirow[b]{2}{*}{$X R C C 1-280$} & \multirow[b]{2}{*}{$X R C C 1-399$} & \multirow[b]{2}{*}{$X P D-751$} & \multicolumn{3}{|c|}{ All women } & \multicolumn{3}{|c|}{ Ever actively smoking women } \\
\hline & & & & $\begin{array}{l}\text { Case/ } \\
\text { Control }\end{array}$ & $\begin{array}{l}\text { Unadjusted OR } \\
\quad(95 \% \mathrm{Cl})\end{array}$ & $\begin{array}{c}\text { Adjusted OR }(95 \% \\
\mathrm{Cl})^{\mathrm{a}}\end{array}$ & $\begin{array}{l}\text { Case/ } \\
\text { Control }\end{array}$ & $\begin{array}{l}\text { Unadjusted OR } \\
(95 \% \mathrm{Cl})\end{array}$ & $\begin{array}{l}\text { Adjusted OR } \\
(95 \% \mathrm{Cl})^{\mathrm{a}}\end{array}$ \\
\hline 0 & $\operatorname{Arg} / \operatorname{Arg}$ & Arg/Arg & $\begin{array}{l}\text { Lys/Lys+ Lys/ } \\
\text { Gln }\end{array}$ & $145 / 159$ & 1.0 & 1.0 & $23 / 46$ & 1.0 & 1.0 \\
\hline 1 & $\operatorname{Arg} / \operatorname{Arg}$ & Arg/Arg & $G / n / G / n$ & $32 / 44$ & $0.80(0.48-1.33)$ & $0.72(0.42-1.25)$ & $8 / 12$ & $1.33(0.48-3.72)$ & $1.20(0.37-3.86)$ \\
\hline 1 & $\operatorname{Arg} / \operatorname{Arg}$ & $\underset{G l n}{\operatorname{Arg} / G \mid n+G / n /}$ & $\begin{array}{l}\text { Lys/Lys+ Lys/ } \\
\text { Gln }\end{array}$ & $172 / 170$ & $1.11(0.81-1.51)$ & $1.15(0.83-1.60)$ & $43 / 48$ & $1.79(0.94-3.43)$ & $1.93(0.93-4.05)$ \\
\hline 1 & $\underset{\mathrm{His}}{\mathrm{Arg} / \mathrm{His}+\mathrm{His} /}$ & $\operatorname{Arg} / \operatorname{Arg}$ & $\begin{array}{l}\text { Lys/Lys+ Lys/ } \\
\text { GIn }\end{array}$ & $45 / 44$ & $1.12(0.70-1.80)$ & $1.19(0.72-1.97)$ & $11 / 15$ & $1.47(0.58-3.70)$ & $1.94(0.69-5.44)$ \\
\hline $\begin{array}{l}1 \text { (any one at risk } \\
\text { genotype) }\end{array}$ & - & - & - & $249 / 258$ & $1.06(0.80-1.41)$ & $1.09(0.81-1.47)$ & $62 / 75$ & $1.65(0.91-3.02)$ & $1.80(0.91-3.56)$ \\
\hline 2 & Arg/Arg & $\underset{G l n}{\operatorname{Arg} / G \mid n+G / n /}$ & $G / n / G / n$ & $46 / 32$ & $1.58(0.95-2.61)$ & $1.80(1.05-3.08)$ & $19 / 5$ & $7.60(2.52-22.0)$ & $12.1(3.52-41.5)$ \\
\hline 2 & $\begin{array}{l}\text { Arg/His } \\
\text { His }\end{array}$ & $\underset{G l n}{\operatorname{Arg} / G|n+G| n /}$ & $\begin{array}{l}\text { Lys/Lys+ Lys/ } \\
\text { Gln }\end{array}$ & $19 / 18$ & $1.16(0.59-2.29)$ & $1.28(0.62-2.64)$ & $3 / 0$ & - & - \\
\hline 2 & $\begin{array}{l}\text { Arg/His+ His/ } \\
\text { His }\end{array}$ & Arg/Arg & $G / n / G / n$ & $13 / 9$ & $1.58(0.66-3.82)$ & $1.36(0.52-3.59)$ & $3 / 2$ & $3.00(0.47-19.2)$ & $3.47(0.44-27.1)$ \\
\hline $\begin{array}{l}2 \text { (any two at risk } \\
\text { genotypes) }\end{array}$ & - & - & - & $78 / 59$ & $1.45(0.97-2.18)$ & $1.54(1.00-2.37)$ & $25 / 7$ & $7.14(2.69-19.0)$ & $10.7(3.62-31.6)$ \\
\hline 3 & $\begin{array}{l}\text { Arg/His+His/ } \\
\text { His }\end{array}$ & $\underset{G / n}{\operatorname{Arg} / G / n+G l n /}$ & $G / n / G / n$ & $4 / 1$ & $4.39(0.49-39.7)$ & $4.76(0.48-47.8)^{b}$ & $1 / 0$ & - & - \\
\hline
\end{tabular}

aOdds ratios (ORs) and confidence intervals (Cls) adjusted for age, first degree family history of breast cancer, age at menarche, number of children, age at first full term pregnancy, history of benign breast disease, weist-to-hip ratio and use of alcohol. ${ }^{b} p$ for trend of having 1,2 or 3 at-risk genotypes 0.042 .

only $67 \%$ for the XRCC1-280 His allele containing genotypes. As the XRCC1-194 Trp variant allele is even less frequent among Finns (approximately 0.03) [45] compared to other Caucasians, and as the amino acid change has not been shown to affect protein function [16], we decided not to include this polymorphism in our study.

The XPD Lys751G/n polymorphism has been suggested to be the most important functional polymorphism in the gene due to major change in the electronic configuration of the respective amino acid in an important interaction domain of the protein [53]. However, no significant overall association with breast cancer was seen in our study for the XPD Lys751G/n genotypes. This was in agreement with the other five studies on the XPD Lys $751 \mathrm{G} / n$ polymorphism and breast cancer risk including one in Finnish [45], one in Danish [46], one in German [47], and two in US Caucasian women $[11,40]$. In contrast, a significant association between the XPD-751 G/n allele and breast cancer risk was seen in a recent study among American women [44]. Moreover, the XPD Asp312Asn polymorphism was recently shown to be associated with breast cancer risk in a German population [47]. We decided not to analyse the XPD Asp312Asn polymorphism as it has been shown to be strictly linked with the Lys751G/n polymorphism [12,38].

When the present study subjects were stratified by stage of disease, the XRCC1-399 G/n allele posed an elevated risk for more advanced stage breast cancer. A similar tendency of increased risk for more advanced stage breast cancer was also seen for the Arg280His polymorphism. It can be hypothesized that defective DNA repair leads to more aggressive and, therefore, more advanced tumours at the time of diagnosis. This was also supported by the association of the XRCC1$399 \mathrm{G} / n$ allele with higher grade tumours. However, as earlier studies on breast cancer have not evaluated the genotype effects by the stage of the disease or tumour grade, these findings remain to be confirmed in future studies.

Smoking alone did not significantly affect breast cancer risk in the present study. This is in agreement with the majority of epidemiological studies on smoking and breast cancer risk, as well as with a recent report of the Collaborative Group on Hormonal Factors in Breast cancer, which concluded that cigarette smoking has little or no effect on the risk of developing breast cancer [3]. There are, however, some studies reporting increased risk in special subgroups, such as women who started to smoke at an early age or before first pregnancy, women smoking high intensity or long duration, passively smoking women, and women with specific genotypes (reviewed in [4]). In our study, a significant interaction was seen between smoking habits and the XRCC1 Arg399G/n ( $p$ $=0.025)$ or $X P D$ Lys751GIn $(p=0.011)$ genotypes. Subjects with the variant $G / n / G / n$ genotypes were at increased risk of developing breast cancer if they had ever smoked. Furthermore, a gene-dosage effect was seen for the XRCC1 Arg399GIn genotype; the increased risk was higher for sub- 
jects carrying two XRCC1-399 G/n alleles. In contrast, the effect of the XPD-751 G/n allele seemed to be recessive. When ever smokers were further stratified by the amount of smoking, the risk estimates remained statistically significant among those who reported having smoked more than five pack-years.

The associations found between the XRCC1 Arg399G/n and/ or XPD Lys751GIn genotypes, smoking, and breast cancer risk are biologically plausible. Cigarette smoke is a rich source of chemical carcinogens and ROS [7]. ROS can initiate lipid peroxidation, oxidize proteins, and cause base damage and DNA single strand breaks that are repaired through BER. Accordingly, the XRCC1-399 G/n/G/n genotype has been found to be related to increased sister chromatid exchange frequencies among smokers [25]. Similarly, a higher frequency of sister chromatid exchange has been reported for carriers of the $399 \mathrm{G} / n$ allele who have smoked $\geq 10$ cigarettes/day [27], and higher levels of tobacco-specific nicotine-derived nitrosamino ketone-induced sister chromatid exchange in cells with the XRCC1-399 G/n allele containing genotypes compared to cells homozygous for the Arg allele [26]. It can thus be hypothesized that the XRCC1-399 G/n allele is associated with increased risk of smoking-dependent cancers. In agreement with this, a higher risk of lung cancer has been reported for the carriers of the XRCC1 G/n/G/n genotype [52], although negative studies also exist $[54,55]$. Breast cancer is not generally regarded as a smoking-dependent cancer. In a recent study on breast cancer, the XRCC1-399 G/n allele was significantly associated with detectable $\mathrm{PAH}$-adducts only in never smokers [33]. They speculated that smoking might stimulate DNA repair and thus the effect seen would be due to other sources of PAHs. Only one earlier study on breast cancer risk has reported a positive association between $X R C C 1$ 399 polymorphism and smoking, but in contrast to our study, the highest risk was seen for subjects who were homozygous for the XRCC1-399 Arg allele [29]. Unfortunately, the possible association with smoking has not been reported in all studies on the XRCC1-399 genotypes [19,22,30,31,36].

In addition to ROS, tobacco smoke includes chemical carcinogens, such as polycyclic aromatic hydrocarbons, aromatic amines and tobacco-specific nitrosamines, that can produce bulky DNA adducts, which are repaired through the NER pathway. There is evidence that tobacco smoke constituents can reach breast tissue [7], and higher levels of the tobacco smoke derived 4-aminobiphenyl adducts [56] and PAH-DNA adducts have been found in breast tissue of breast cancer cases [57-59]. Mammary epithelial cells are capable of metabolising and activating these compounds. Therefore, the hypothesis is that breast cancer cases with suboptimal DNA repair capacity would have less efficient removal of these adducts, thus making them more vulnerable to the hazardous effects of these compounds. Accordingly, the XPD-751 G/n allele has been associated with increased DNA adduct levels in never smokers [39] and in tumour tissue from breast cancer cases [40], as well as with suboptimal DNA repair [11,38]. A recent meta-analysis showed an association between the $X P D-751 \mathrm{G} / \mathrm{n} / \mathrm{G} / \mathrm{n}$ genotype and increased lung cancer risk [42]. This was not, however, confirmed by another recent meta-analysis [60]. In accordance with our results, a similar increased breast cancer risk was recently seen among currently smoking American women with the XPD-751 G/n/G/n genotype [44]. Similarly to our study, no clear pattern with duration of smoking was seen. This could partly be due to low numbers in these strata, or it can be hypothesized that a higher intensity of smoking is needed to see the difference between these genotypes, while in subjects with lower intensity but longer duration the repair system is capable of overcoming the harmful effects.

Alcohol is a known risk factor for breast cancer; increased estrogen and androgen levels have been observed in alcohol consuming women [61]. Alcohol consumption is also believed to contribute to oxidative stress [62]. We therefore analysed the results also stratified by the use of alcohol. A significantly increased three-fold risk of breast cancer was seen for women who carried the XPD-751 G/n/G/n genotype and used alcohol weekly or daily. No earlier studies on the XPD genotype and breast cancer have reported an association with the use of alcohol. However, a 2.59 -fold (95\% Cl 1.25-5.34) risk was seen for squamous cell carcinoma of head and neck among current drinkers carrying the XPD-751 G/n/G/n genotype compared to those drinking the same amount but with the other genotypes [43].

When the gene-gene interactions were studied, clear combined effects were seen, especially among ever smoking women; smoking women with any two at-risk genotypes were at remarkably increased risk of breast cancer (OR 10.7, 95\% $\mathrm{Cl}$ 3.62-31.6) compared to smoking women without these genotypes. These effects were mainly due to XRCC1-399 and $X P D-751$ genotypes while the $X R C C 1-280$ genotype was a minor contributor, possibly partly due to the very low frequency of the XRCC1-280His variant alleles. When the combined effect was studied according to the number of at-risk alleles, subjects with any three variant alleles were found to be at increased risk. There was no subject who simultaneously carried more than four at-risk alleles in these three polymorphic sites.

It should be noted that even if our study involved a reasonable number of study subjects, the numbers in some subgroup analyses were small, and the statistical power to detect significant point-estimates is, therefore, low. Furthermore, due to multiple comparisons performed in the study, the possibility of chance findings should be borne in mind. However, in addition to the plausibility of the findings, the dose-response seen by the number of at-risk alleles or genotypes and amounts smoked support the causality of the findings. 
In case-control studies, the possibility of selection and recall bias should be considered. However, the detailed data about smoking habits and other life style factors were collected prior to diagnosis, and the exposure to passive smoking, quite often disregarded, was taken into account. It is also unlikely that selection would be related to an individual's genotype. As the statistical analyses were performed within exposure groups and not between them, the possibility of biased estimates is further reduced.

Even though the present findings are biologically plausible, the possibility of the association with another gene polymorphism in the same region should be considered. Accordingly, it was recently reported that three markers, $R A I, A S E-1$ and ERCC1, in the same chromosomal region 19q13.2-3 define a high-risk haplotype that poses women under 55 years to a significantly increased breast cancer risk [46]. In that study, no association was seen with the XRCC1 or XPD genotypes but the effects were not studied by smoking habits. In our study, no difference in the risk estimates was seen by age.

Finally, it should be noted that not all the known polymorphisms in the BER and NER pathways were analysed in this study. For the XRCC1 Arg194Trp polymorphism, association has been seen with increased mutagen sensitivity [63], risk of developing an adverse response to radiotherapy [19], as well as interaction with high intake of fruits and vegetables [33], and it could thus be hypothesized to affect breast cancer risk in population where it exists in higher frequency. Similarly, polymorphism has been detected in another gene, OGG1, encoding an enzyme important in the BER pathway, as well as numerous other genes encoding for possibly important repair enzymes in the NER pathway, namely $X P A, X P C, X P F$ and XPG.

\section{Conclusion}

We found a statistically significant association between the $X R C C 1$ and XPD genotypes and breast cancer risk in Finnish smoking women, especially when enzymes in both DNA repair pathways were defective. This finding is of particular interest as smoking, being the main preventable risk factor for cancer, is constantly increasing among female adolescents in many countries, including Finland. However, it should be borne in mind that the two studied DNA repair genes account for only a small part of the known genetic variations in these pathways and, therefore, most probably do not explain the whole picture, but should be considered in the context of other possible genes. These results, together with our earlier results concerning polymorphisms in estrogen metabolizing enzymes [64], support the view that it is crucial to study simultaneously the effect of environmental exposures and genotypes in order to better understand and reveal the complex associations between genetic factors, life style and cancer.

\section{Competing interests}

The authors declare that they have no competing interests.

\section{Authors' contributions}

$\mathrm{KM}$ was responsible for supervising the laboratory work, for performing statistical analyses, and for manuscript preparation. VK participated in the design and coordination of the study, helped to draft the manuscript and acts as the principal clinician in the study group. PS, PS and LH carried out the genotyping analyses and drafted the manuscript. ME participated in the design and coordination of the study and was clinical coordinator of collection of study patient material. VMK performed histopathological analyses of all cases, and helped to draft the manuscript. MU has been involved in the planning of the study, collection of clinical data, in particular with respect to the genetic part of the study, and he has commented on the manuscript in the writing phase. $\mathrm{AH}$ participated in the design and coordination of the molecular epidemiology part of the study, was responsible for acquisition of funding for the molecular epidemiology part, and was involved in the preparation of the manuscript. All authors read and approved the final manuscript.

\section{Acknowledgements}

We thank our colleagues at the Kuopio Cancer Research Center, and Ms AK Lyytinen, RN for data collection. The support from the Finnish Cancer Society, Academy of Finland and EVO funds from Kuopio University Hospital are gratefully acknowledged.

\section{References}

1. Key TJ, Verkasalo PK, Banks E: Epidemiology of breast cancer. Lancet Oncol 2001, 2:133-140.

2. Million Women Study Collaborators: Breast cancer and hormone-replacement therapy in the Million Women Study. Lancet 2003, 362:419-427.

3. Collaborative Group on Hormonal Factors in Breast Cancer: Alcohol, tobacco and breast cancer - collaborative reanalysis of individual data from 53 epidemiological studies, including $\mathbf{5 8 , 5 1 5}$ women with breast cancer and 95,067 women without the disease. $\mathrm{Br} J$ Cancer 2002, 87:1234-1245.

4. Terry PD, Rohan TE: Cigarette smoking and the risk of breast cancer in women: a review of the literature. Cancer Epidemiol Biomarkers Prev 2002, 11:953-971.

5. International Agency for Research on Cancer: Tobacco Smoke and Involuntary Smoking Volume 83. Lyon: IARC Scientific Publications; 2004.

6. Reynolds P, Hurley S, Goldberg DE, Anton-Culver H, Bernstein L, Deapen D, Horn-Ross PL, Peel D, Pinder R, Ross RK, et al:: Active smoking, household passive smoking, and breast cancer: evidence from the California Teachers Study. J Natl Cancer Inst 2004, 96:29-37.

7. Hecht SS: Tobacco smoke carcinogens and breast cancer. Environ Mol Mutagen 2002, 39:119-126.

8. Baron JA, La Vecchia C, Levi F: The antiestrogenic effect of cigarette smoking in women. Am J Obstet Gynecol 1990, 162:502-514.

9. de Boer JG: Polymorphisms in DNA repair and environmental interactions. Mutat Res 2002, 509:201-210.

10. Berwick M, Vineis P: Markers of DNA repair and susceptibility to cancer in humans: an epidemiologic review. J Natl Cancer Inst 2000, 92:874-897.

11. Shi Q, Wang LE, Bondy ML, Brewster A, Singletary SE, Wei Q: Reduced DNA repair of benzo[a]pyrene diol epoxide-induced adducts and common XPD polymorphisms in breast cancer patients. Carcinogenesis 2004, 25:1695-1700. 
12. Shen MR, Jones IM, Mohrenweiser $\mathrm{H}$ : Nonconservative amino acid substitution variants exist at polymorphic frequency in DNA repair genes in healthy humans. Cancer Res 1998, 58:604-608.

13. Goode EL, Ulrich CM, Potter JD: Polymorphisms in DNA repair genes and associations with cancer risk. Cancer Epidemiol Biomarkers Prev 2002, 11:1513-1530.

14. Caldecott KW: XRCC1 and DNA strand break repair. DNA Repair (Amst) 2003, 2:955-969.

15. Caldecott KW, Aoufouchi S, Johnson P, Shall S: XRCC1 polypeptide interacts with DNA polymerase beta and possibly poly (ADP-ribose) polymerase, and DNA ligase III is a novel molecular 'nick-sensor' in vitro. Nucleic Acids Res 1996, 24:4387-4394.

16. Savas S, Kim DY, Ahmad MF, Shariff M, Ozcelik H: Identifying functional genetic variants in DNA repair pathway using protein conservation analysis. Cancer Epidemiol Biomarkers Prev 2004, 13:801-807.

17. Thompson LH, West MG: XRCC1 keeps DNA from getting stranded. Mutat Res 2000, 459:1-18

18. Tuimala J, Szekely G, Gundy S, Hirvonen A, Norppa H: Genetic polymorphisms of DNA repair and xenobiotic-metabolizing enzymes: role in mutagen sensitivity. Carcinogenesis 2002, 23:1003-1008.

19. Moullan N, Cox DG, Angele S, Romestaing P, Gerard JP, Hall J: Polymorphisms in the DNA repair gene XRCC1, breast cancer risk, and response to radiotherapy. Cancer Epidemiol Biomarkers Prev 2003, 12:1168-1174.

20. Lunn RM, Langlois RG, Hsieh LL, Thompson CL, Bell DA: XRCC1 polymorphisms: effects on aflatoxin B1-DNA adducts and glycophorin A variant frequency. Cancer Res 1999, 59:2557-2561.

21. Sigurdson AJ, Hauptmann M, Chatterjee N, Alexander BH, Doody MM, Rutter JL, Struewing JP: Kin-cohort estimates for familial breast cancer risk in relation to variants in DNA base excision repair, BRCA1 interacting and growth factor genes. BMC Cancer 2004, 4:9

22. Chacko P, Rajan B, Joseph T, Mathew BS, Pillai MR: Polymorphisms in DNA repair gene XRCC1 and increased genetic susceptibility to breast cancer. Breast Cancer Res Treat 2005, 89:15-21.

23. Shall S, de Murcia G: Poly(ADP-ribose) polymerase-1: what have we learned from the deficient mouse model? Mutat Res 2000, 460:1-15.

24. Hu JJ, Smith TR, Miller MS, Mohrenweiser HW, Golden A, Case LD: Amino acid substitution variants of APE1 and XRCC1 genes associated with ionizing radiation sensitivity. Carcinogenesis 2001, 22:917-922.

25. Duell EJ, Wiencke JK, Cheng TJ, Varkonyi A, Zuo ZF, Ashok TD, Mark EJ, Wain JC, Christiani DC, Kelsey KT: Polymorphisms in the DNA repair genes XRCC1 and ERCC2 and biomarkers of DNA damage in human blood mononuclear cells. Carcinogenesis 2000, 21:965-971.

26. Abdel-Rahman SZ, El-Zein RA: The 399GIn polymorphism in the DNA repair gene XRCC1 modulates the genotoxic response induced in human lymphocytes by the tobacco-specific nitrosamine NNK. Cancer Lett 2000, 159:63-71.

27. Lei YC, Hwang SJ, Chang CC, Kuo HW, Luo JC, Chang MJ, Cheng TJ: Effects on sister chromatid exchange frequency of polymorphisms in DNA repair gene XRCC1 in smokers. Mutat Res 2002, 519:93-101.

28. Kim SU, Park SK, Yoo KY, Yoon KS, Choi JY, Seo JS, Park WY, Kim JH, Noh DY, Ahn SH, et al:: XRCC1 genetic polymorphism and breast cancer risk. Pharmacogenetics 2002, 12:335-338.

29. Duell EJ, Millikan RC, Pittman GS, Winkel S, Lunn RM, Tse CK, Eaton A, Mohrenweiser HW, Newman B, Bell DA: Polymorphisms in the DNA repair gene XRCC1 and breast cancer. Cancer Epidemiol Biomarkers Prev 2001, 10:217-222.

30. Smith TR, Miller MS, Lohman K, Lange EM, Case LD, Mohrenweiser HW, Hu JJ: Polymorphisms of XRCC1 and XRCC 3 genes and susceptibility to breast cancer. Cancer Lett 2003, 190:183-190.

31. Smith TR, Levine EA, Perrier ND, Miller MS, Freimanis RI, Lohman $\mathrm{K}$, Case LD, Xu J, Mohrenweiser HW, Hu JJ: DNA-repair genetic polymorphisms and breast cancer risk. Cancer Epidemiol Biomarkers Prev 2003, 12:1200-1204.
32. Han J, Hankinson SE, De Vivo I, Spiegelman D, Tamimi RM Mohrenweiser HW, Colditz GA, Hunter DJ: A prospective study of XRCC1 haplotypes and their interaction with plasma carotenoids on breast cancer risk. Cancer Res 2003, 63:8536-8541.

33. Shen J, Gammon MD, Terry MB, Wang L, Wang Q, Zhang F, Teitelbaum SL, Eng SM, Sagiv SK, Gaudet MM, et al.: Polymorphisms in XRCC1 modify the association between polycyclic aromatic hydrocarbon-DNA adducts, cigarette smoking, dietary antioxidants, and breast cancer risk. Cancer Epidemiol Biomarkers Prev 2005, 14:336-342.

34. Figueiredo JC, Knight JA, Briollais L, Andrulis IL, Ozcelik H: Polymorphisms XRCC1-R399Q and XRCC3-T241M and the risk of breast cancer at the Ontario site of the Breast Cancer Family Registry. Cancer Epidemiol Biomarkers Prev 2004, 13:583-591.

35. Shu XO, Cai Q, Gao YT, Wen W, Jin F, Zheng W: A populationbased case-control study of the Arg399GIn polymorphism in DNA repair gene XRCC1 and risk of breast cancer. Cancer Epidemiol Biomarkers Prev 2003, 12:1462-1467.

36. Deligezer U, Dalay N: Association of the XRCC1 gene polymorphisms with cancer risk in Turkish breast cancer patients. Exp Mol Med 2004, 36:572-575.

37. Lehmann AR: The xeroderma pigmentosum group D (XPD) gene: one gene, two functions, three diseases. Genes Dev 2001, 15:15-23.

38. Qiao Y, Spitz MR, Guo Z, Hadeyati M, Grossman L, Kraemer KH Wei $Q$ : Rapid assessment of repair of ultraviolet DNA damage with a modified host-cell reactivation assay using a luciferase reporter gene and correlation with polymorphisms of DNA repair genes in normal human lymphocytes. Mutat Res 2002, 509:165-174

39. Matullo G, Palli D, Peluso M, Guarrera S, Carturan S, Celentano E, Krogh V, Munnia A, Tumino R, Polidoro S, et al: XRCC1, XRCC3, XPD gene polymorphisms, smoking and (32)P-DNA adducts in a sample of healthy subjects. Carcinogenesis 2001 , 22:1437-1445.

40. Tang D, Cho S, Rundle A, Chen S, Phillips D, Zhou J, Hsu Y, Schnabel F, Estabrook A, Perera FP: Polymorphisms in the DNA repair enzyme XPD are associated with increased levels of PAH-DNA adducts in a case-control study of breast cancer. Breast Cancer Res Treat 2002, 75:159-166.

41. Lunn RM, Helzlsouer KJ, Parshad R, Umbach DM, Harris EL, Sanford KK, Bell DA: XPD polymorphisms: effects on DNA repair proficiency. Carcinogenesis 2000, 21:551-555.

42. Hu Z, Wei Q, Wang X, Shen H: DNA repair gene XPD polymorphism and lung cancer risk: a meta-analysis. Lung Cancer 2004, 46:1-10.

43. Sturgis EM, Zheng R, Li L, Castillo EJ, Eicher SA, Chen M, Strom SS, Spitz MR, Wei Q: XPD/ERCC2 polymorphisms and risk of head and neck cancer: a case-control analysis. Carcinogenesis 2000, 21:2219-2223

44. Terry MB, Gammon MD, Zhang FF, Eng SM, Sagiv SK, Paykin AB Wang $\mathrm{Q}$, Hayes S, Teitelbaum SL, Neugut Al, et al:: Polymorphism in the DNA repair gene XPD, polycyclic aromatic hydrocarbon-DNA adducts, cigarette smoking, and breast cancer risk. Cancer Epidemiol Biomarkers Prev 2004, 13:2053-2058.

45. Forsti A, Angelini S, Festa F, Sanyal S, Zhang Z, Grzybowska E Pamula J, Pekala W, Zientek H, Hemminki K, et al:: Single nucleotide polymorphisms in breast cancer. Oncol Rep 2004, 11:917-922.

46. Nexo BA, Vogel U, Olsen A, Ketelsen T, Bukowy Z, Thomsen BL, Wallin $\mathrm{H}$, Overvad $\mathrm{K}$, Tjonneland A: A specific haplotype of single nucleotide polymorphisms on chromosome 19q13.2-3 encompassing the gene RAl is indicative of post-menopausal breast cancer before age 55 . Carcinogenesis 2003 24:899-904.

47. Justenhoven C, Hamann U, Pesch B, Harth V, Rabstein S, Baisch C, Vollmert C, Illig T, Ko YD, Bruning T, et al.: ERCC2 genotypes and a corresponding haplotype are linked with breast cancer risk in a German population. Cancer Epidemiol Biomarkers Prev 2004, 13:2059-2064.

48. Mitrunen K, Kataja V, Eskelinen M, Kosma VM, Kang D, Benhamou S, Vainio H, Uusitupa M, Hirvonen A: Combined COMT and GST genotypes and hormone replacement therapy associated breast cancer risk. Pharmacogenetics 2002, 12:67-72.

49. Slattery ML, Edwards SL, Caan BJ, Kerber RA, Potter JD Response rates among control subjects in case-control studies. Ann Epidemiol 1995, 5:245-249. 
50. Dybdahl M, Vogel U, Frentz G, Wallin H, Nexo BA: Polymorphisms in the DNA repair gene XPD: correlations with risk and age at onset of basal cell carcinoma. Cancer Epidemiol Biomarkers Prev 1999, 8:77-81.

51. Vodicka P, Kumar R, Stetina R, Sanyal S, Soucek P, Haufroid V, Dusinska M, Kuricova M, Zamecnikova M, Musak L, et al.: Genetic polymorphisms in DNA repair genes and possible links with DNA repair rates, chromosomal aberrations and singlestrand breaks in DNA. Carcinogenesis 2004.

52. Divine KK, Gilliland FD, Crowell RE, Stidley CA, Bocklage TJ, Cook $\mathrm{DL}$, Belinsky SA: The XRCC1 399 glutamine allele is a risk factor for adenocarcinoma of the lung. Mutat Res 2001, 461:273-278.

53. Benhamou S, Sarasin A: ERCC2/XPD gene polymorphisms and cancer risk. Mutagenesis 2002, 17:463-469.

54. Ratnasinghe D, Yao SX, Tangrea JA, Qiao YL, Andersen MR, Barrett MJ, Giffen CA, Erozan Y, Tockman MS, Taylor PR: Polymorphisms of the DNA repair gene XRCC1 and lung cancer risk. Cancer Epidemiol Biomarkers Prev 2001, 10:119-123.

55. Chen S, Tang D, Xue K, Xu L, Ma G, Hsu Y, Cho SS: DNA repair gene XRCC 1 and XPD polymorphisms and risk of lung cancer in a Chinese population. Carcinogenesis 2002, 23:1321-1325.

56. Faraglia B, Chen SY, Gammon MD, Zhang Y, Teitelbaum SL, Neugut Al, Ahsan H, Garbowski GC, Hibshoosh H, Lin D, et al.: Evaluation of 4-aminobiphenyl-DNA adducts in human breast cancer: the influence of tobacco smoke. Carcinogenesis 2003, 24:719-725.

57. Santella RM, Gammon MD, Zhang YJ, Motykiewicz G, Young TL, Hayes SC, Terry MB, Schoenberg JB, Brinton LA, Bose S, et al.: Immunohistochemical analysis of polycyclic aromatic hydrocarbon-DNA adducts in breast tumours tissue. Cancer Lett 2000, 154:143-149.

58. Rundle A, Tang D, Hibshoosh H, Estabrook A, Schnabel F, Cao W, Grumet S, Perera FP: The relationship between genetic damage from polycyclic aromatic hydrocarbons in breast tissue and breast cancer. Carcinogenesis 2000, 21:1281-1289.

59. Li D, Wang M, Dhingra K, Hittelman WN: Aromatic DNA adducts in adjacent tissues of breast cancer patients: clues to breast cancer etiology. Cancer Res 1996, 56:287-293.

60. Benhamou S, Sarasin A: ERCC2/XPD gene polymorphisms and lung cancer: a HuGE review. Am J Epidemiol 2005, 161:1-14.

61. Singletary KW, Gapstur SM: Alcohol and breast cancer: review of epidemiologic and experimental evidence and potential mechanisms. JAMA 2001, 286:2143-2151.

62. Wright RM, McManaman JL, Repine JE: Alcohol-induced breast cancer: a proposed mechanism. Free Radic Biol Med 1999, 26:348-354.

63. Wang $Y$, Spitz MR, Zhu Y, Dong Q, Shete S, Wu X: From genotype to phenotype: correlating XRCC1 polymorphisms with mutagen sensitivity. DNA Repair (Amst) 2003, 2:901-908.

64. Mitrunen K, Hirvonen A: Molecular epidemiology of sporadic breast cancer. The role of polymorphic genes involved in oestrogen biosynthesis and metabolism. Mutat Res 2003, 544:9-41. 